Guinea pig ascorbate status predicts tetrahydrobiopterin plasma concentration and oxidation ratio in vivo

Mortensen, Alan; Andersen, Stine Hasselholt; Tveden-Nyborg, Pernille; Lykkesfeldt, Jens

Published in:

Nutrition Research

DOI:

10.1016/j.nutres.2013.07.006

Publication date:

2013

Document version

Early version, also known as pre-print

Citation for published version (APA):

Mortensen, A., Andersen, S. H., Tveden-Nyborg, P., \& Lykkesfeldt, J. (2013). Guinea pig ascorbate status

predicts tetrahydrobiopterin plasma concentration and oxidation ratio in vivo. Nutrition Research, 33(10), 859867. https://doi.org/10.1016/j.nutres.2013.07.006 


\title{
Guinea pig ascorbate status predicts tetrahydrobiopterin plasma concentration and oxidation ratio in vivo
}

\author{
Alan Mortensen, Stine Hasselholt, Pernille Tueden-Nyborg, Jens Lykkesfeldt*
}

Faculty of Health and Medical Sciences, University of Copenhagen, Denmark

\section{A R T I C L E I N F O}

Article history:

Received 19 December 2012

Revised 1 July 2013

Accepted 7 July 2013

Keywords:

Ascorbic acid

Tetrahydrobiopterin

Dihydrobiopterin

Guinea pig

In vivo oxidation

\begin{abstract}
A B S T R A C T
Tetrahydrobiopterin $\left(\mathrm{BH}_{4}\right)$ is an essential co-factor of nitric oxide synthases and is easily oxidized to dihydrobiopterin $\left(\mathrm{BH}_{2}\right)$ which promotes endothelial nitric oxide synthase uncoupling and deleterious superoxide production. Vitamin $C$ has been shown to improve endothelial function by different mechanisms, some involving $\mathrm{BH}_{4}$. The hypothesis of the present study was that vitamin C status, in particular low levels, influences biopterin redox status in vivo. Like humans, the guinea pig lacks the ability to synthesize vitamin $\mathrm{C}$ and was therefore used as model. Seven day old animals ( $n=10$ /group) were given a diet containing 100, 250, 500, 750, 1000, or 1500 ppm vitamin C until euthanasia at age 60-64 days. Blood samples were drawn from the heart and analyzed for ascorbate, dehydroascorbic acid (DHA), $\mathrm{BH}_{4}$ and $\mathrm{BH}_{2}$ by high-performance liquid chromatography. Plasma $\mathrm{BH}_{4}$ levels were found to be significantly lower in animals fed $100 \mathrm{ppm}$ vitamin $\mathrm{C}$ compared to all other groups $\left(\mathrm{P}<.05\right.$ or less). $\mathrm{BH}_{2}$ levels were not significantly different between groups but the $\mathrm{BH}_{2}$-to- $\mathrm{BH}_{4}$ ratio was higher in the group fed $100 \mathrm{ppm}$ vitamin $\mathrm{C}$ $\left(P<.001\right.$ all cases). Significant positive correlations between $\mathrm{BH}_{4}$ and ascorbate and between $\mathrm{BH}_{2}$-to- $\mathrm{BH}_{4}$ ratio and DHA were observed $\left(\mathrm{P}<.0001\right.$ both cases). Likewise, $\mathrm{BH}_{2}$-to$\mathrm{BH}_{4}$ ratio was negatively correlated with ascorbate $(\mathrm{P}<.0001)$ as was $\mathrm{BH}_{4}$ and DHA $(\mathrm{P}<$ .005). In conclusion, the redox status of plasma biopterins, essentially involved in vasodilation, depends on the vitamin $C$ status in vivo. Thus, ingestion of insufficient quantities of vitamin $\mathrm{C}$ not only leads to vitamin $\mathrm{C}$ deficiency but also to increased $\mathrm{BH}_{4}$ oxidation which may promote endothelial dysfunction.
\end{abstract}

(c) 2013 Elsevier Inc. All rights reserved.

\section{Introduction}

The endothelium plays a crucial role in maintaining vascular homeostasis. A dysfunctional endothelium is observed in many diseases and conditions such as diabetes, coronary artery disease, atherosclerosis and hypertension [1]. Endothelial dysfunction (ED) is in part due to an imbalance between vasoconstricting and vasodilating substances produced by or acting on the endothelium. ED is commonly associated with decreased bioavailability of nitric oxide (NO) due to less NO production by the endothelium and/or an increase in reaction between NO and reactive oxygen species [2]. NO is produced by nitric oxide synthase (NOS), of which there are three types: endothelial NOS (eNOS), inducible NOS and neuronal NOS. Tetrahydrobiopterin $\left(\mathrm{BH}_{4}\right)$ is an essential co-factor of the three NOSs [3]. $\mathrm{BH}_{4}$ is easily oxidized to

\footnotetext{
Abbreviations: $\mathrm{BH}_{2}$, dihydrobiopterin; $\mathrm{BH}_{4}$, tetrahydrobiopterin; DHA, dehydroascorbic acid; DTE, dithioerythritol; ED, endothelial dysfunction; eNOS, endothelial nitric oxide synthase; HPLC, high performance liquid chromatography; MPA, meta-phosphoric acid; NOS, nitric oxide synthase.

* Corresponding author. Department of Veterinary Disease Biology, University of Copenhagen, Ridebanevej 9, 1, DK-1870 Frederiksberg C, Denmark.

E-mail address: jopl@sund.ku.dk (J. Lykkesfeldt).
} 
dihydrobiopterin $\left(\mathrm{BH}_{2}\right)$, which may be further oxidized to biopterin. During $\mathrm{BH}_{4}$ deficiency, eNOS enters what is called an 'uncoupled' state and produces superoxide rather than NO [4], which may react to form the strong oxidant peroxynitrite. It has been found that $\mathrm{BH}_{4}$ and $\mathrm{BH}_{2}$ bind to eNOS with equal affinity [5,6], but whereas binding of $\mathrm{BH}_{4}$ leads to production of $\mathrm{NO}$, binding of $\mathrm{BH}_{2}$ leads to formation of superoxide [4]. Superoxide can oxidize $\mathrm{BH}_{4}$ directly or through the formation of peroxynitrite [7] leading to decreased production of NO and further increased production of superoxide. It has been suggested that the ratio of $\mathrm{BH}_{2}$ to $\mathrm{BH}_{4}$, rather than the absolute levels of $\mathrm{BH}_{4}$ and $\mathrm{BH}_{2}$, is the best predictor of endothelial function [5,6,8-11].

Vitamin C deficiency has been associated with increased risk of cardiovascular disease in many epidemiological studies [12] and this has prompted investigations into the potential mechanisms by which ascorbate may influence cardiovascular function. Ascorbate has been shown in in vitro studies to act as specific redox modulator in the NO synthesis by keeping $\mathrm{BH}_{4}$ reduced [13-15]. Also, several mechanisms involving eNOS have been suggested through which ascorbate can potentially increase the bioavailability of NO (Fig. 1). Moreover, high doses of vitamin $\mathrm{C}$ has been shown to improve endothelial function in people with compromised endothelial function [1]. We therefore hypothesized that commonly observed hypovitaminosis C whilst not leading to scurvy-the ultimate clinical manifestation of vitamin C deficiency-may indirectly affect endothelial function by resulting in an unfavorable ratio of $\mathrm{BH}_{4} / \mathrm{BH}_{2}$. In the present study, we used our guinea pig model to test, if dietary vitamin $\mathrm{C}$ predicts the plasma concentrations and ratio of $\mathrm{BH}_{4} / \mathrm{BH}_{2}$ in vivo. In contrast to all other mammals, primates (including humans), bats and guinea pigs specifically lack the ability to synthesize vitamin $C$ due to a mutation in the gene encoding for gulonolactone oxidase catalyzing the last step in the biosynthesis [16]. Thus, the guinea pig constitutes a unique and well-validated model for studying low levels of vitamin $\mathrm{C}$ comparable to those found in large human subpopulations [17-20].

\section{Methods and materials}

\subsection{Materials}

7,8-dihydro-L-biopterin $\left(\mathrm{BH}_{2}\right)$ and (6R)-5,6,7,8-tetrahydrobiopterin $\left(\mathrm{BH}_{4}\right)$ were from Shircks Laboratories (Jena, Switzerland). Tris(2-carboxyethyl)phosphine hydrochloride and disodium ethylenediaminetetraacetate dihydrate $\left(\mathrm{Na}_{2}\right.$-EDTA) were purchased from VWR-Bie \& Berntsen A/S (Herlev, Denmark). 1,4Dithioerythritol (DTE), and meta-phosphoric acid (MPA) were obtained from Sigma-Aldrich (Brøndby, Denmark). All other chemicals were of the highest quality available. All solutions were made in Milli-Q water.

\subsection{Animals}

The experiment was approved by the Animal Experiments Inspectorate under the Ministry of Food, Agriculture and Fisheries. Sixty Hartley guinea pigs (HA-SIFE150200, Charles River Laboratories, Kisslegg, Germany), 7 days of age, were marked with a subcutaneous microchip in the neck, weight stratified and randomized into six feeding groups upon arrival to our animal facility. All groups received a purified diet (Research Diets, Inc, New Brunswick, NJ, USA), the only difference being the amount of vitamin C. Ingredients are provided in Table. Diets with a final concentration of 100, 250, 500, 750, 1000, or 1500 ppm vitamin C were made from feed containing 0 ppm vitamin C (D11091304), 727.6 ppm vitamin C (D11091305) and $2128.4 \mathrm{ppm}$ vitamin C (D11091306) by analysis. The animals had free access to water and hay. We have previously shown that even the lowest dose of vitamin C provided does not result in scurvy [17,21,22]. Animals were group housed in floor pens in an enriched environment at 22 \pm $2^{\circ} \mathrm{C}$ with a $12: 12 \mathrm{~h}$ light-dark cycle, inspected daily by trained personnel and weighted twice weekly. At 60-64 days of age, the guinea pigs were anaesthetized by using isofluran inhalation (Isoba vet, MSD Animal Health, the Netherlands).

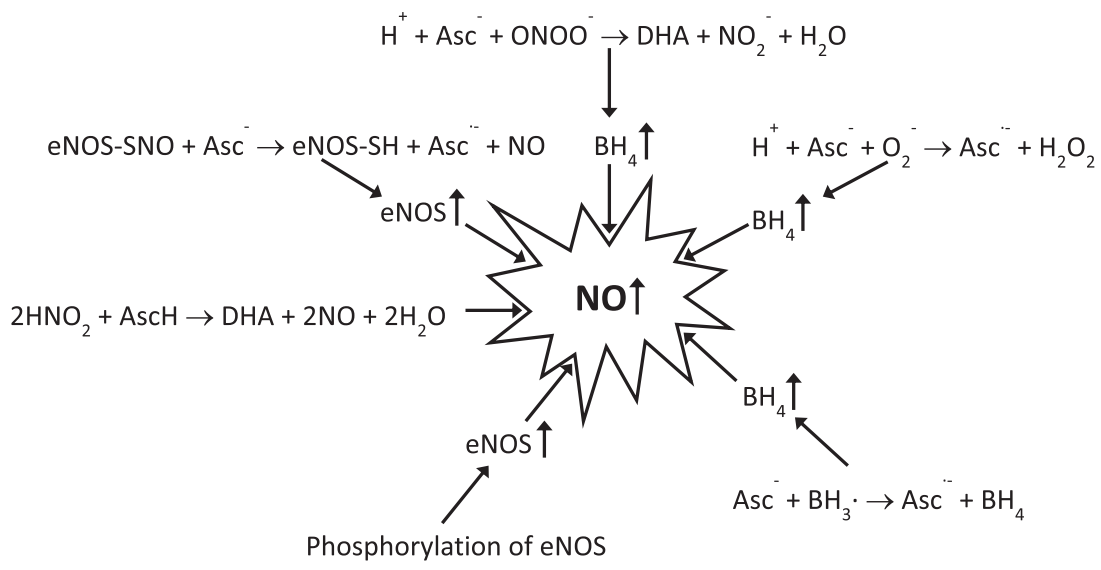

Fig. 1 - Putative mechanisms by which vitamin C may increase NO bioavailability. Vitamin C may increase eNOS activity by increasing phosphorylation [46] and decreasing S-nitrosylation [47]. Vitamin C may also increase $\mathrm{BH}_{4}$ bioavailability by scavenging peroxynitrite [45] and superoxide [7] or by recycling one-electron oxidized $\mathrm{BH}_{4}[7,41]$. Ascorbic acid may also reduce nitrite to yield NO [48], though this process is likely only relevant at low $\mathrm{pH}$. 
Table - Ingredient composition of the diets fed to guinea pigs.

\begin{tabular}{|c|c|c|c|}
\hline \multirow{2}{*}{$\frac{\text { Ingredient }}{\text { Diet (stock) }^{\mathrm{a}}}$} & \multicolumn{3}{|c|}{ g } \\
\hline & \#D11081304 & \#D11081305 & \#D11081306 \\
\hline Soy protein & 80 & 80 & 80 \\
\hline Casein & 120 & 120 & 120 \\
\hline L-Methionine & 5 & 5 & 5 \\
\hline Corn starch & 315 & 315 & 315 \\
\hline Maltodextrin,10 & 35 & 35 & 35 \\
\hline Sucrose & 350 & 350 & 350 \\
\hline Cellulose, Bw200 & 100 & 100 & 100 \\
\hline Guar gum & 25 & 25 & 25 \\
\hline Lard & 20 & 20 & 20 \\
\hline Soybean oil & 25 & 25 & 25 \\
\hline Mineral mix ${ }^{b}$ & 75 & 75 & 75 \\
\hline Vitamin $\operatorname{mix}^{\mathrm{c}}$ & 10 & 10 & 10 \\
\hline $\begin{array}{l}\text { Ascorbic acid } \\
\text { phosphate, L } \\
(33 \% \text { active })^{d}\end{array}$ & 0 & 2.5 & 7.1 \\
\hline Choline bitatrate & 2 & 2 & 2 \\
\hline Total & 1162 & 1164.5 & 1169.1 \\
\hline \multicolumn{4}{|c|}{$\begin{array}{l}\text { all diets were produced by Research Diets Inc. Individual vitamin C } \\
\text { regimes applied in the different experimental groups (100-250-500- } \\
750-1000 \text { and } 1500 \text { ppm vitamin C) were achieved by titrating the } \\
\text { three diets to meet the desired levels. Batch \# 0 ppm vitamin C } \\
\text { (D11091304), } 700 \text { ppm ( } 727.6 \text { ppm by analysis) vitamin C (D11091305), } \\
\text { and } 2000 \text { ppm (2128.4 ppm by analysis) vitamin C (D11091306). } \\
\text { b Mineral mix S20001. } \\
\text { c Vitamin mix V23901. } \\
\text { d Provided by Rovimix Stay-C } 35 \text {. }\end{array}$} \\
\hline
\end{tabular}

Subsequently, a thoracotomy was performed and an intracardial blood sample obtained using a syringe with an 18G, 40 $\mathrm{mm}$ needle that had been flushed with $15 \% \mathrm{~K}_{3}$-EDTA. Animals were finally euthanized by decapitation.

\subsection{Ascorbic acid determination}

Blood samples were immediately centrifuged for 2 minutes at $16000 \times g\left(4^{\circ} \mathrm{C}\right)$ and stabilized with $10 \%(\mathrm{w} / \mathrm{v})$ MPA containing 2 $\mathrm{mmol} / \mathrm{L} \mathrm{Na}_{2}$-EDTA as reported previously [23] and stored at $-80^{\circ} \mathrm{C}$ until analysis. The stability of ascorbate and dehydroascorbic acid (DHA) in MPA stabilized plasma has been studied previously and found adequate in preserving the in vivo equilibrium $[24,25]$. Ascorbate and total vitamin C (ascorbate + DHA) following reduction were quantified by high-performance liquid chromatography (HPLC) with coulometric determination and DHA concentrations were assessed by subtraction of ascorbate from total vitamin $\mathrm{C}$ using uric acid as endogenous internal standard [24]. The within- and between-day coefficients of variation for the complete assay were less than $1.5 \%$ and $3.5 \%$, respectively [26].

\subsection{Biopterin determination}

Blood samples for biopterin analysis were immediately added $4 \%$ DTE to yield a final concentration of $0.1 \%$ DTE. The blood sample was centrifuged for $1 \mathrm{~min}$ and the plasma was separated and frozen at $-80^{\circ} \mathrm{C}$ until further analysis.

$\mathrm{BH}_{2}$ and $\mathrm{BH}_{4}$ were determined by HPLC modified from Hyland [27]. The HPLC system consisted of an Agilent 1100 thermostatted autosampler, an Agilent 1200 binary pump, an Agilent 1200 fluorescence detector, and an Ultimate 3000 column compartment from Dionex. $\mathrm{BH}_{4}$ was determined using a 5011A analytical cell (ESA, Inc) with potentials of $-400 \mathrm{mV}$ (electrode 1) and $125 \mathrm{mV}$ (electrode 2) controlled by a CouloChem II detector (ESA, Inc.) - detection was at electrode 2. $\mathrm{BH}_{2}$ was determined by fluorescence (excitation wavelength $275 \mathrm{~nm}$ and emission wavelength $442 \mathrm{~nm}$ ) after oxidation of $\mathrm{BH}_{2}$ to the more strongly fluorescent biopterin by a conditioning cell (5021A from ESA, Inc) running at $500 \mathrm{mV}$.

The column was a Gemini $\mathrm{C}_{18}(250 \times 4.6 \mathrm{~mm}, 5 \mu \mathrm{m})$ from Phenomenex. The samples were eluted with $100 \%$ aqueous buffer containing $50 \mu \mathrm{mol} / \mathrm{L} \mathrm{Na}_{2}$-EDTA and $50 \mathrm{mmol} / \mathrm{L}$ ammonium acetate-acetic acid buffer at $\mathrm{pH} 4.8$. The column was thermostatted at $30^{\circ} \mathrm{C}$ and the eluent flow was $1 \mathrm{~mL} / \mathrm{min}$.

Plasma samples were thawed immediately prior to analysis. After thawing, plasma was added 50\% MPA in the ratio 9:1 (v/v). After spinning for $1 \mathrm{~min}$. $(16000 \times \mathrm{g})$, the supernatant was neutralized with $5 \mathrm{~mol} / \mathrm{L} \mathrm{NaOH}$ and analyzed immediately. Quantification was done using external standards. The within- and between-day coefficients of variation for the complete assay were less than 5 and 3.5\%, respectively.

\subsection{Statistical analyses}

Data are presented as means \pm SD unless otherwise indicated. A sample size of 10 was chosen with the purpose of identifying a $30 \%$ effect of vitamin C deficiency with a $30 \%$ SD on each average measurement and a power of $80 \%$. Multiple regression analysis and analysis of variance were performed using Statistica (Statsoft version 9.0, Tulsa, OK, USA). In case of significance, Tukey's post hoc test was used for individual comparisons. $\mathrm{P}<.05$ was considered statistically significant.

\section{Results}

As expected, plasma vitamin $\mathrm{C}$ was found to increase significantly with level of vitamin $C$ in the diet (Fig. 2). However, plasma $\mathrm{BH}_{4}$ levels were also affected by the amount of vitamin $\mathrm{C}$ in the diet. Thus, guinea pigs fed $100 \mathrm{ppm}$ vitamin $C$ had lower plasma levels of $\mathrm{BH}_{4}(\mathrm{P}<.05$ or less) than animals fed higher doses of vitamin $C$ (Fig. 3A); there were no significant differences between the other groups. $\mathrm{BH}_{2}$ levels were unaffected by the level of vitamin $\mathrm{C}$ in the diet, leading to a significantly higher $\mathrm{BH}_{2}$-to- $\mathrm{BH}_{4}$ ratio in the group fed 100 ppm vitamin $C(P<.0001)$ with no differences among the other groups (Fig. 3B).

Plasma ascorbate levels were in the range $5-100 \square \mathrm{M}$, while biopterin levels ranged from around $100 \mathrm{nmol} / \mathrm{L}$ to around 400 $\mathrm{nmol} / \mathrm{L}$. Plasma levels of biopterins and ascorbate were highly correlated. As Fig. 4A shows, the $\mathrm{BH}_{4}$ plasma level was positively correlated with total vitamin $\mathrm{C}$ :

$\mathrm{C}\left(\mathrm{BH}_{4}\right) / \mathrm{nM}=146+1.24 \times \mathrm{C}($ vitamin $\mathrm{C}) / \mathrm{M} \quad P<.0001$

$\mathrm{BH}_{4}$ plasma concentration was also negatively correlated with the vitamin $\mathrm{C}$ oxidation ratio (percentage of DHA of total vitamin C) (Fig. 4B):

$\mathrm{C}\left(\mathrm{BH}_{4}\right) / \mathrm{nM}=271-4.04 \mathrm{DHA} / \% \quad P<.005$ 
$\mathrm{BH}_{2}$ plasma concentration, on the other hand, was not correlated with vitamin $\mathrm{C}$ plasma levels. However, the ratio of $\mathrm{BH}_{2}$ to $\mathrm{BH}_{4}$ was. Thus, guinea pigs with high levels of total vitamin $\mathrm{C}$ tended to have lower $\mathrm{BH}_{2}$-to- $\mathrm{BH}_{4}$ ratios (Fig. $5 \mathrm{~A}$ ):

$\mathrm{C}\left(\mathrm{BH}_{2}\right) / \mathrm{C}\left(\mathrm{BH}_{4}\right)=0.12-0.00103 \times \mathrm{C}($ vitamin $\mathrm{C}) / \mathrm{M} \quad P<.0001$

and higher percentage of DHA correlated with higher $\mathrm{BH}_{2}$-to$\mathrm{BH}_{4}$ ratio (Fig. 5B):

$\mathrm{C}\left(\mathrm{BH}_{2}\right) / \mathrm{C}\left(\mathrm{BH}_{4}\right)=-0.0055+0.0046 \times \mathrm{DHA} / \% \quad P<.0001$.

\section{Discussion}

A considerable epidemiological literature has found that vitamin C deficiency in humans is consistently associated with increased risk of developing cardiovascular disease and stroke (for recent studies see [28-31]). In contrast, all major intervention studies have been unable to demonstrate an effect of vitamin C supplementation on cardiovascular risk (for recent studies see [32-35]). However, as pointed out by us elsewhere, none of the latter studies has unfortunately recruited and thus studied the effect of supplementation in deficient individuals which is of major importance considering the particular non-linear saturation kinetics of vitamin C $[20,12,36]$. Thus, properly performed animal model studies of vitamin C deficiency are indeed warranted. In the present study, we wanted to investigate the in vivo relationship between plasma biopterin redox status, vitamin $C$ ingestion and plasma vitamin $\mathrm{C}$ using guinea pigs as a model as a negative effect of vitamin $\mathrm{C}$ deficiency on biopterin redox status in vivo may constitute an indirect rationale underlying the association between poor vitamin C status and increased risk of heart disease observed in humans.

Some smaller intervention studies have shown a beneficialbut typically transient-effect of vitamin C on endothelial function in people suffering from various conditions such as

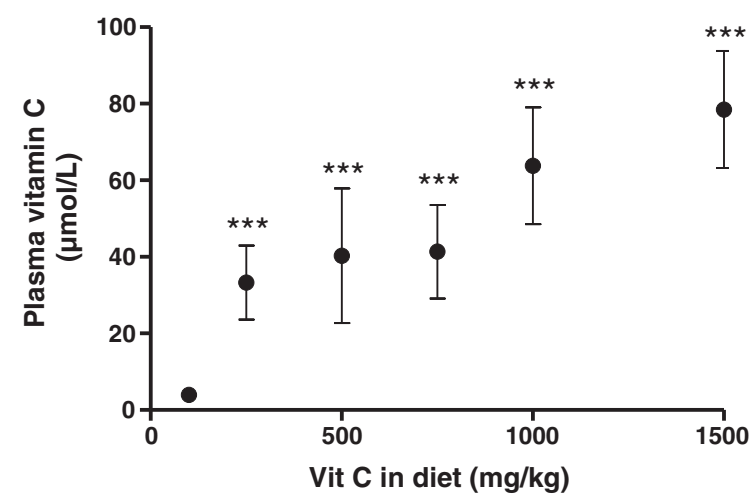

Fig. 2 - Plasma vitamin C as a function of vitamin C in diet. Guinea pigs ( $n=10$ in each group) were exposed to different vitamin C concentrations for two months. Plasma vitamin C was significantly lower in the group fed $100 \mathrm{ppm}$ vitamin C compared to all other groups. Data are presented as means \pm SD. ${ }^{* * *} P<.001$.

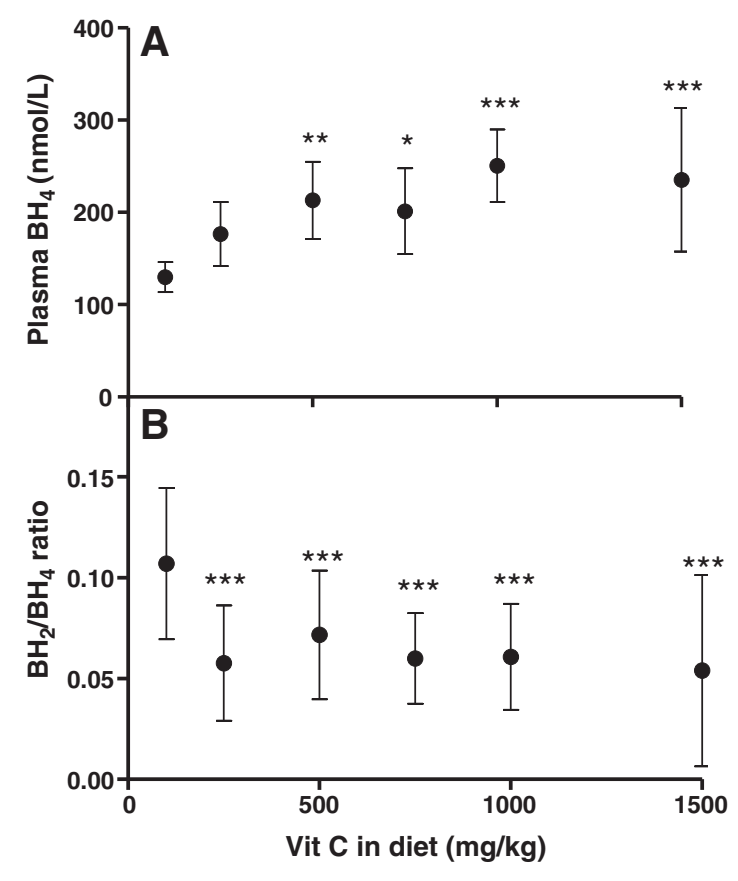

Fig. 3 - Plasma $\mathrm{BH}_{4}$ level and $\mathrm{BH}_{2}$-to- $\mathrm{BH}_{4}$ ratio as a function of vitamin $C$ in the diet. Guinea pigs ( $n=10$ in each group) were exposed to different vitamin $\mathrm{C}$ concentrations for two months. $\mathrm{BH}_{4}$ levels (A) were significantly lower and $\mathrm{BH}_{2}$-to$\mathrm{BH}_{4}$ ratio (B) was significantly higher of the $100 \mathrm{ppm}$ group compared to the other groups. Data are presented as means \pm SD. ${ }^{*} \mathrm{P}<.05,{ }^{* *} \mathrm{P}<.01,{ }^{* * *} \mathrm{P}<.001$.

diabetes, coronary artery disease, hypertension, and inflammation, while other studies found no effect of such intervention (for a review see [1]). Numerous possible mechanisms behind a putative effect of vitamin $C$ on endothelial function have been suggested, e.g. decrease in low-density lipoprotein oxidation, scavenging of superoxide, release of nitric oxide from S-nitrosothiols, reduction of nitrite to nitric oxide, and activation of either eNOS or smooth muscle guanylate cyclase [37]. Of particular relevance to our observations are studies looking at the relationship between vitamin $\mathrm{C}$ and eNOS activity, since $\mathrm{BH}_{4}$ is a necessary co-factor of eNOS and plasma levels of vitamin $C$ and redox status of biopterins are linked. Vitamin C could exert its positive effect on eNOS activity directly through regulation of eNOS activity or indirectly by increasing the $\mathrm{BH}_{4}$ bioavailability. Several potential mechanisms involving eNOS have been suggested through which ascorbate could increase the bioavailability of NO. In a number of studies, it was found that incubation of endothelial cells in the presence of vitamin $C$ increased intracellular $\mathrm{BH}_{4}$ levels [13-15], whereas another study found only a non-significant increase of intracellular $\mathrm{BH}_{4}$ when endothelial cells were incubated with vitamin $\mathrm{C}$ alone but a marked $176 \%$ increase when cells were treated with E. coli endotoxin and vitamin C together [38]. Likewise, incubation of mouse macrophages with vitamin $\mathrm{C}$ was found to increase intracellular levels of $\mathrm{BH}_{4}$ [39]. Based on in vitro experiments it has been suggested that vitamin $\mathrm{C}$ exerted its positive effect on $\mathrm{BH}_{4}$ levels by preventing oxidation of $\mathrm{BH}_{4}$ or by recycling one-electron oxidized $\mathrm{BH}_{4}[7,14,40,41]$. One way that ascorbate 
could prevent oxidation of $\mathrm{BH}_{4}$ is by scavenging reactive oxygen species before they react with $\mathrm{BH}_{4}$, which is very easily oxidized. Several reactive oxygen species exist but of particular relevance to NO bioavailability is superoxide and peroxynitrite. Superoxide reacts with both ascorbate and $\mathrm{BH}_{4}$ with a rate constant of 3 to $4 \cdot 10^{5} \mathrm{~mol} / \mathrm{L}^{-1} \mathrm{~s}^{-1}[42,43]$. The much higher plasma concentration of ascorbate compared to $\mathrm{BH}_{4}$ means that ascorbate at least theoretically is capable of protecting $\mathrm{BH}_{4}$ from oxidation by superoxide. However, superoxide reacts much faster with NO forming peroxynitrite than with either ascorbate or $\mathrm{BH}_{4}$. Thus, the typically micromolar plasma concentrations of ascorbate have been found inadequate in preventing superoxide from reacting with NO. In fact, ascorbate concentrations of $10 \mathrm{mmol} / \mathrm{L}$ are needed to compete with NO for superoxide [44]. In contrast, in vitro experiments with endothelial cells, ascorbate concentrations were found in the low millimolar range [45] suggesting that ascorbate would be able to scavenge at least part of the superoxide generated intracellularly. Moreover, although peroxynitrite reacts 10 times faster with $\mathrm{BH}_{4}$ than with ascorbate [7], the 1000-fold higher concentration of ascorbate compared to $\mathrm{BH}_{4}$ in human plasma suggests that peroxynitrite may react with ascorbate over $\mathrm{BH}_{4}$ in vivo. Another possible mechanism by which ascorbate could affect the bioavailability of $\mathrm{BH}_{4}$ is through regulation of the synthesis of $\mathrm{BH}_{4} \cdot \mathrm{BH}_{4}$ is synthesized in vivo by two mechanisms referred to as de novo synthesis and the salvage pathway, respectively [3]. It was
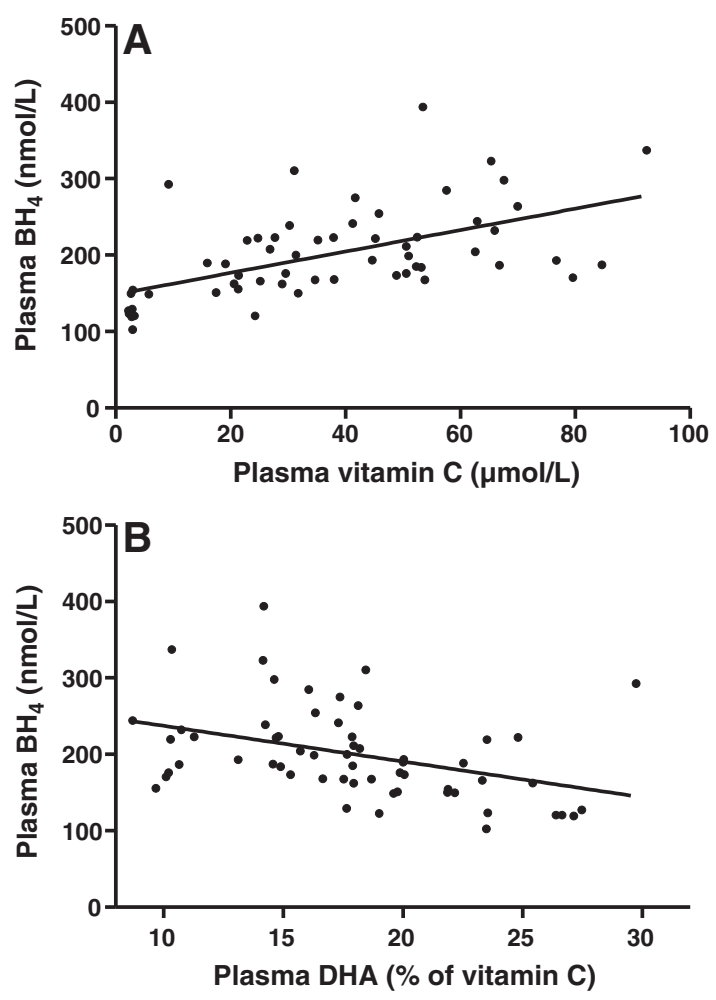

Fig. 4 - Correlation between $\mathrm{BH}_{4}$ and vitamin C. Data from all animals $(n=60)$ were included in the analysis. Plasma $\mathrm{BH}_{4}$ levels were highly $(P<.0001)$ positively correlated with plasma vitamin $C(A)$ and highly $(P<.0001)$ negatively correlated with DHA (B).
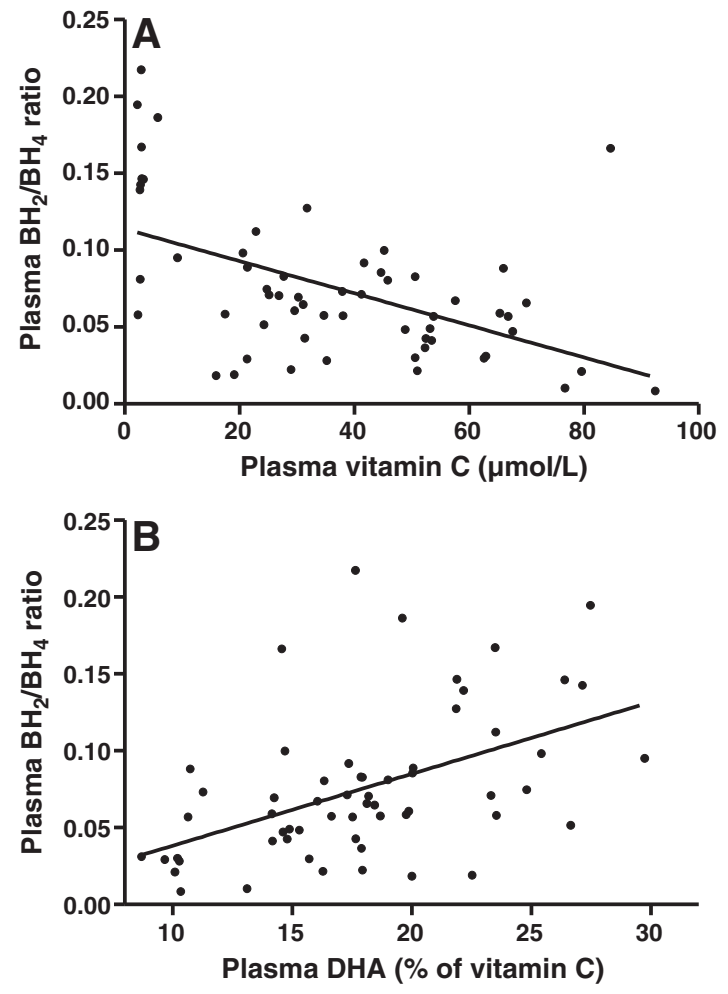

Fig. 5 - Correlation between biopterin ratio and vitamin C. Data from all animals $(n=60)$ were included in the analysis. Plasma $\mathrm{BH}_{2}$-to- $\mathrm{BH}_{4}$ ratio is highly $(\mathrm{P}<.0001)$ negatively correlated with plasma vitamin $C(A)$ and highly $(P<.0001)$ positively correlated with DHA (B).

found that ascorbate had no effect on the expression or activity of the rate-limiting enzyme (GTPCH-I) in the de novo synthesis of $\mathrm{BH}_{4}[14]$ and, so far, no effect of ascorbate on the salvage pathway has been reported.

Ascorbate could also affect the NO bioavailability by directly influencing the activity of eNOS. In a very recent report, it was shown that vitamin $\mathrm{C}$ increases phosphorylation of eNOS-Ser ${ }^{1177}$ and decreases phosphorylation of eNOS$\mathrm{Thr}^{495}$, which is indicative of increased eNOS activity [46]. Besides phosphorylation, eNOS activity is also regulated by Snitrosylation of its cysteins, whereby S-nitrosylation leads to reduced activity. It has been shown that ascorbate was able to denitrosylate eNOS, hereby increasing eNOS activity [47]. Finally, ascorbic acid could also increase NO bioavailability directly by reducing nitrite-formed by oxidation of NO-to NO, a process utilized in the curing of meat. However, this reaction requires an acidic environment, such as that found in the stomach, to proceed at an appreciable rate. Thus, at $\mathrm{pH}$ 3.63 the reaction was found to proceed at an appreciable rate but was found to be much slower at pH 5.49 [48]. Consequently, in the vasculature, enzymatic reduction of nitrite to NO is more likely than reduction by ascorbate [49].

Few studies have looked at the effect of vitamin $C$ on in vivo biopterin levels. d'Uscio et al observed that long-term vitamin $\mathrm{C}$ supplementation increased aortic $\mathrm{BH}_{4}$ levels and decreased $\mathrm{BH}_{2}$-to- $\mathrm{BH}_{4}$ levels in wild-type mice, whereas $\mathrm{BH}_{2}$ levels were unaffected [50], findings that are in-line with our observations although their study was conducted in a species 
capable of synthesizing vitamin C. Likewise, it was found that $\mathrm{BH}_{4}$ levels were decreased and $\mathrm{BH}_{2}$ levels were increased in diabetic rat hearts compared to control rat hearts and that vitamin C could alleviate these changes [51]. In a study in guinea pigs, neutrophils isolated from scorbutic guinea pigs were found to contain less $\mathrm{BH}_{4}$ than the neutrophils from control animals [52].

In the present study, the $\mathrm{BH}_{4}$ plasma level ranged from 100 to $400 \mathrm{nmol} / \mathrm{L}$ with a mean of around $200 \mathrm{nmol} / \mathrm{L}$. $\mathrm{BH}_{2}$ levels were typically between 5 and $30 \mathrm{nmol} / \mathrm{L}$ with an average of $15 \mathrm{nmol} / \mathrm{L}$. The biopterin plasma levels have, to the best of our knowledge, not previously been measured in guinea pigs. The level of plasma $\mathrm{BH}_{4}$ in our guinea pigs is an order of magnitude higher than that found in humans, which in various studies have been found to range from a few $\mathrm{nmol} / \mathrm{L}$ up to $35 \mathrm{nmol} / \mathrm{L}$ [8,53-84]. $\mathrm{BH}_{4}$ in human plasma typically comprises around $50 \%$ to $80 \%$ of total biopterins whereas in guinea pigs, more than $90 \%$ is on the reduced form. Compared to other animal species, guinea pig biopterin plasma levels are comparable to those found in studies using mice and rats [57,66,83,85-91], whereas larger animals such as dogs, cats, and monkeys have biopterin levels more similar to those found in humans $[65,66,83,92]$. Thus, one limitation of our study is that the impact of vitamin C deficiency on biopterin status may not translate between guinea pigs and humans as only the vitamin C level is similar between the two species while guinea pig biopterin levels are higher. On the other hand one might speculate that the impact of vitamin C deficiency could be even larger in humans as the low biopterin levels presumably are more prone to oxidation.

Our studies show that high plasma vitamin $\mathrm{C}$ levels correlate with high $\mathrm{BH}_{4}$ plasma levels and a low $\mathrm{BH}_{2}$-to- $\mathrm{BH}_{4}$ ratio in guinea pigs. However, plasma concentration of vitamin $\mathrm{C}$ is not the only predictor of $\mathrm{BH}_{4}$ plasma levels and $\mathrm{BH}_{2}$-to- $\mathrm{BH}_{4}$ ratio: DHA, a measure of oxidative stress, also correlates with $\mathrm{BH}_{4}$ and $\mathrm{BH}_{2}$-to- $\mathrm{BH}_{4}$ ratio. Thus, a high proportion of DHA was found to correlate with a high $\mathrm{BH}_{2}$-to- $\mathrm{BH}_{4}$ ratio, also indicating a state of increased oxidative stress.

In conclusion, we can accept our hypothesis that biopterin redox status depends on plasma vitamin $\mathrm{C}$ levels in that low levels of plasma vitamin $\mathrm{C}$ leads to a higher $\mathrm{BH}_{2}$-to- $\mathrm{BH}_{4}$ ratio. Thus, our data provide in vivo support for a relationship between ascorbate status and biopterin bioavailability and may therefore indirectly explain clinical observations showing a negative impact of vitamin $\mathrm{C}$ deficiency on cardiovascular health since a high $\mathrm{BH}_{2}$-to- $\mathrm{BH}_{4}$ ratio has been linked to endothelial dysfunction in several studies [5,6,8-11]. However, the human relevance of the ascorbate-dependent maintenance of a reduced $\mathrm{BH}_{4}$ pool clearly needs to be confirmed in controlled clinical studies.

\section{Acknowledgment}

We wish to thank Annie Bjergby Kristensen, Elisabeth Veyhe Andersen and Joan Frandsen for excellent technical assistance. This work was supported by the Danish National Research Councils and the LIFEPHARM Centre for in vivo pharmacology. All authors declare no conflicts of interest that could influence the present work.

\section{R E F E R E N C E S}

[1] Frikke-Schmidt H, Lykkesfeldt J. Role of marginal vitamin C deficiency in atherogenesis: in vivo models and clinical studies. Basic Clin Pharmacol Toxicol 2009;104:419-33.

[2] Katusic ZS. Vascular endothelial dysfunction: does tetrahydrobiopterin play a role? Am J Physiol 2001;281: H981-6.

[3] Werner ER, Blau N, Thöny B. Tetrahydrobiopterin: biochemistry and pathophysiology. Biochem J 2011;438: 397-414.

[4] Vásquez-Vivar J, Martásek P, Whitsett J, Joseph J, Kalyanaraman B. The ratio between tetrahydrobiopterin and oxidized tetrahydrobiopterin analogues controls superoxide release from endothelial nitric oxide synthase: an EPR spin trapping study. Biochem J 2002;362:733-9.

[5] Crabtree MJ, Smith CL, Lam G, Goligorsky MS, Gross SS. Ratio of 5,6,7,8-tetrahydrobiopterin to 7,8-dihydrobiopterin in endothelial cells determines glucose-elicited changes in NO vs. superoxide production by eNOS. Am J Physiol 2008;294: H1530-40.

[6] Mohan S, Patel H, Bolinaga J, Soekamto N, Achu L, Teklemariam K. Dihydrobiopterin $\left(\mathrm{BH}_{2}\right)$ : key determinant in influencing arginine mediated endothelial tolerance and dysfunction. Am J Biochem Biotech 2012;8:54-62.

[7] Kuzkaya N, Weissmann N, Harrison DG, Dikalov S. Interactions of peroxynitrite, tetrahydrobiopterin, ascorbic acid, and thiols. J Biol Chem 2003;278:22546-54.

[8] Takeda M, Yamashita T, Shinohara M, Sasaki N, Takaya T, Nakajima K, et al. Plasma tetrahydrobiopterin/ dihydrobiopterin ratio: a possible marker of endothelial dysfunction. Circ J 2009;73:955-62.

[9] Noguchi K, Hamadate N, Matsuzaki T, Sakanashi M, Nakasone J, Uchida T, et al. Increasing dihydrobiopterin causes dysfunction of endothelial nitric oxide synthase in rats in vivo. Am J Physiol 2011;301:H721-9.

[10] Kar S, Kavdia M. Modeling of biopterin-dependent pathways of eNOS for nitric oxide and superoxide production. Free Radic Biol Med 2011;51:1411-27.

[11] Crabtree MJ, Tatham AL, Al-Wakeel Y, Warrick N, Hale AB, Cai $S$, et al. Quantitative regulation of intracellular endothelial nitric-oxide synthase (eNOS) coupling by both tetrahydrobiopterin-eNOS stoichiometry and biopterin redox status. J Biol Chem 2009;284:1136-44.

[12] Lykkesfeldt J, Poulsen HE. Is vitamin C supplementation beneficial? Lessons learned from randomised controlled trials. Br J Nutr 2010;103:1251-9.

[13] Huang A, Vita JA, Venema RC, Keaney JF. Ascorbic acid enhances endothelial nitric-oxide synthase activity by increasing intracellular tetrahydrobiopterin. J Biol Chem 2000;275:17399-406.

[14] Heller R, Unbehaun A, Schellenberg B, Mayer B, WernerFelmayer G, Werner ER. L-ascorbic acid potentiates endothelial nitric oxide synthesis via a chemical stabilization of tetrahydrobiopterin. J Biol Chem 2001;276:40-7.

[15] Baker TA, Milstien S, Katusic ZS. Effect of vitamin C on the availability of tetrahydrobiopterin in human endothelial cells. J Cardiovasc Pharmacol 2001;37:333-8.

[16] Chatterjee IB, Majumder AK, Nandi BK, Subramanian N. Synthesis and some major functions of vitamin $C$ in animals. Ann New York Acad Sci 1975;258:24-47.

[17] Tveden-Nyborg P, Hasselholt S, Miyashita N, Moos T, Poulsen HE, Lykkesfeldt J. Chronic vitamin C deficiency does not 
accelerate oxidative stress in ageing brains of guinea pigs. Basic Clin Pharmacol Toxicol 2012;110:524-9.

[18] Jensen PO, Lykkesfeldt J, Bjarnsholt T, Hougen HP, Hoiby N, Ciofu O. Poor antioxidant status exacerbates oxidative stress and inflammatory response to Pseudomonas aeruginosa lung infection in guinea pigs. Basic Clin Pharmacol Toxicol 2012;110:353-8.

[19] Schjoldager JG, Tveden-Nyborg P, Lykkesfeldt J. Prolonged maternal vitamin $C$ deficiency overrides preferential fetal ascorbate transport but does not influence perinatal survival in guinea pigs. Br J Nutr 2013:1-7.

[20] Tveden-Nyborg P, Lykkesfeldt J. Does vitamin C deficiency increase lifestyle-associated vascular disease progression? evidence based on experimental and clinical studies. Antioxid Redox Signal 2013. http://dx.doi.org/10.1089/ars. 2013.5382 [Epub ahead of print].

[21] Tveden-Nyborg P, Johansen LK, Raida Z, Villumsen CK, Larsen JO, Lykkesfeldt J. Vitamin C deficiency in early postnatal life impairs spatial memory and reduces the number of hippocampal neurons in guinea pigs. Am J Clin Nutr 2009;90: 540-6.

[22] Tveden-Nyborg P, Vogt L, Schjoldager JG, Jeannet N, Hasselholt S, Paidi MD, et al. Maternal vitamin C deficiency during pregnancy persistently impairs hippocampal neurogenesis in offspring of guinea pigs. PLoS ONE 2012;7: e48488.

[23] Lykkesfeldt J. Determination of ascorbic acid and dehydroascorbic acid in biological samples by highperformance liquid chromatography using subtraction methods: reliable reduction with tris[2-carboxyethyl] phosphine hydrochloride. Anal Biochem 2000;282:89-93.

[24] Lykkesfeldt J. Ascorbate and dehydroascorbic acid as reliable biomarkers of oxidative stress: analytical reproducibility and long-term stability of plasma samples subjected to acidic deproteinization. Cancer Epidemiol Biomarkers Prev 2007;16: 2513-6.

[25] Lykkesfeldt J. Ascorbate and dehydroascorbic acid as biomarkers of oxidative stress: validity of clinical data depends on vacutainer system used. Nutr Res 2012;32:66-9.

[26] Lykkesfeldt J, Loft S, Poulsen HE. Determination of ascorbic acid and dehydroascorbic acid in plasma by highperformance liquid chromatography with coulometric detection-are they reliable biomarkers of oxidative stress? Anal Biochem 1995;229:329-35.

[27] Hyland K. Estimation of tetrahydro-, dihydro- and fully oxidized pterins by high-performance liquid chromatography using sequential electrochemical and fluorometric detection. J Chromatogr Biomed Appl 1985;343:35-41.

[28] Agarwal M, Mehta PK, Dwyer JH, Dwyer KM, Shircore AM, Nordstrom CK, et al. Differing relations to early atherosclerosis between vitamin C from supplements vs. food in the Los angeles atherosclerosis study: a prospective cohort study. Open Cardiovasc Med J 2012;6:113-21.

[29] Myint PK, Luben RN, Welch AA, Bingham SA, Wareham NJ, Khaw KT. Plasma vitamin C concentrations predict risk of incident stroke over $10 \mathrm{y}$ in 20649 participants of the European Prospective Investigation into Cancer Norfolk prospective population study. Am J Clin Nutr 2008;87: 64-9.

[30] Langlois M, Duprez D, Delanghe J, De BM, Clement DL. Serum vitamin $C$ concentration is low in peripheral arterial disease and is associated with inflammation and severity of atherosclerosis. Circulation 2001;103:1863-8.

[31] Simon JA, Hudes ES, Browner WS. Serum ascorbic acid and cardiovascular disease prevalence in U.S. adults. Epidemiology 1998;9:316-21.

[32] Heart Protection Study Collaborative G. MRC/BHF Heart Protection Study of antioxidant vitamin supplementation in 20,536 high-risk individuals: a randomised placebocontrolled trial. Lancet 2002;360:23-33.

[33] Hercberg S, Galan P, Preziosi P, Bertrais S, Mennen L, Malvy D, et al. The SU.VI.MAX Study: a randomized, placebo-controlled trial of the health effects of antioxidant vitamins and minerals. Arch Intern Med 2004;164:2335-42.

[34] Cook NR, Albert CM, Gaziano JM, Zaharris E, MacFadyen J, Danielson E, et al. A randomized factorial trial of vitamins C and $E$ and beta carotene in the secondary prevention of cardiovascular events in women: results from the Women's Antioxidant Cardiovascular Study. Arch Intern Med 2007;167: 1610-8.

[35] Avenell A, Campbell MK, Cook JA, Hannaford PC, Kilonzo MM, McNeill G, et al. Effect of multivitamin and multimineral supplements on morbidity from infections in older people (MAVIS trial): pragmatic, randomised, double blind, placebo controlled trial. Brit Med J 2005;331:324-9.

[36] Frei B, Birlouez-Aragon I, Lykkesfeldt J. Authors' perspective: what is the optimum intake of vitamin C in humans? Crit Rev Food Sci Nutr 2012;52:815-29.

[37] May JM. How does ascorbic acid prevent endothelial dysfunction? Free Radic Biol Med 2000;28:1421-9.

[38] Mittermayer F, Pleiner J, Schaller G, Zorn S, Namiranian K, Kapiotis S, et al. Tetrahydrobiopterin corrects Escherichia coli endotoxin-induced endothelial dysfunction. Am J Physiol 2005;289:H1752-7.

[39] Nakai K, Urushihara M, Kubota Y, Kosaka H. Ascorbate enhances iNOS activity by increasing tetrahydrobiopterin in RAW 264.7 cells. Free Radic Biol Med 2003;35:929-37.

[40] Valent S, Toth M. Spectrophotometric analysis of the protective effect of ascorbate against spontaneous oxidation of tetrahydrobiopterin in aqueous solution: kinetic characteristics and potentiation by catalase of ascorbate action. Int J Biochem Cell Biol 2004;36:1266-80.

[41] Patel KB, Stratford MRL, Wardman P, Everett SA. Oxidation of tetrahydrobiopterin by biological radicals and scavenging of the trihydrobiopterin radical by ascorbate. Free Radic Biol Med 2002;32:203-11.

[42] Gotoh N, Niki E. Rates of interactions of superoxide with vitamin $\mathrm{E}$, vitamin $\mathrm{C}$ and related compounds as measured by chemiluminescence. Biochim Biophys Acta 1992;1115: 201-7.

[43] Vásquez-Vivar J, Whitsett J, Martásek P, Hogg N, Kalyanaraman B. Reaction of tetrahydrobiopterin with superoxide: EPR-kinetic analysis and characterization of the pteridine radical. Free Radic Biol Med 2001;31:975-85.

[44] Jackson TS, Xu A, Vita JA, Keaney JF. Ascorbate prevents the interaction of superoxide and nitric oxide only at very high physiological concentrations. Circ Res 1998;83:916-22.

[45] May JM, Qu Z-C, Qiao H. Transfer of ascorbic acid across the vascular endothelium: mechanism and self-regulation. Am Physiol 2009;297:C169-78.

[46] Ladurner A, Schmitt CA, Schachner D, Atanasov AG, Werner ER, Dirsch VM, et al. Ascorbate stimulates endothelial nitric oxide synthase enzyme activity by rapid modulation of its phosphorylation status. Free Radic Biol Med 2012;52:2082-90.

[47] Erwin PA, Lin AJ, Golan DE, Michel T. Receptor-regulated dynamic S-nitrosylation of endothelial nitric-oxide synthase in vascular endothelial cells. J Biol Chem 2005;280:19888-94.

[48] Izumi K, Cassens RG, Greaser ML. Reaction of nitrite with ascorbic acid and its significant role in nitrite-cured food. Meat Sci 1989;26:141-53.

[49] Lundberg JO, Weitzberg E. Nitrite reduction to nitric oxide in the vasculature. Am J Physiol 2008;295:H477-8.

[50] d'Uscio LV, Milstien S, Richardson D, Smith L, Katusic ZS. Long-term vitamin $C$ treatment increases vascular tetrahydrobiopterin levels and nitric oxide synthase activity. Circ Res 2003;92:88-95. 
[51] Okazaki T, Otani H, Shimazu T, Yoshioka K, Fujita M, Iwasaka T. Ascorbic acid and $\mathrm{N}$-acetyl cysteine prevent uncoupling of nitric oxide synthase and increase tolerance to ischemia/reperfusion injury in diabetic rat heart. In Free Radic Res, vol. 45. pp. 1173-83: Life Sci; 2011:1173-83.

[52] Chatterjee M, Saluja R, Kumar V, Jyoti A, Kumar Jain G, Kumar Barthwal M, et al. Ascorbate sustains neutrophil NOS expression, catalysis, and oxidative burst. Free Radic Biol Med 2008;45:1084-93.

[53] Fekkes D, Voskuilen-Kooijman A. Quantitation of total biopterin and tetrahydrobiopterin in plasma. Clin Biochem 2007;40:411-3.

[54] Fiege B, Ballhausen D, Kierat L, Leimbacher W, Goriounov D, Schircks B, et al. Plasma tetrahydrobiopterin and its pharmacokinetics following oral administration. Mol Gen Metab 2004;81:45-51.

[55] Powers AG, Young JH, Clayton BE. Estimation of tetrahydrobiopterin and other pterins in plasma by isocratic liquid chromatography with electrochemical and fluorimetric detection. J Chromatogr Biomed Appl 1988;432: 321-8.

[56] Blair JA, Whitburn SB, Pheasant AE, Leeming RJ, Morar C, Al-Beir A. A critical appraisal of methods for the quantitative analysis of tetrahydrobiopterin, dihydrobiopterin and biopterin in human urine, serum and CSF. Edited by Blair JA. Walter de Gruyter \& Co.:165-9.

[57] Fukushima T, Nixon JC. Analysis of reduced forms of biopterin in biological tissues and fluids. Anal Biochem 1980;102:176-88.

[58] Antoniades C, Shirodaria C, Van AT, Cunnington C, Tegeder I, Lotsch J, et al. GCH1 haplotype determines vascular and plasma biopterin availability in coronary artery disease effects on vascular superoxide production and endothelial function. J Am Coll Cardiol 2008;52:158-65.

[59] Hashimoto R, Ozaki N, Ohta T, Kasahara Y, Kaneda N, Nagatsu T. The plasma tetrahydrobiopterin levels in patients with affective disorders. Biol Psychiat 1990;28: 526-8.

[60] Oppenheimer DI, Dorenbaum A, Okhamafe A, Foehr E, Castillo S, Kostel PJ. Methods of administering tetrahydrobiopterin, associated compositions, and methods of measuring. WO: (Biomarin Pharmaceutical Inc.,USA). 2008.

[61] Antoniades C, Shirodaria C, Crabtree M, Rinze R, Alp N, Cunnington $\mathrm{C}$, et al. Altered plasma versus vascular biopterins in human atherosclerosis reveal relationships between endothelial nitric oxide synthase coupling, endothelial function, and inflammation. Circulation 2007;116:2851-9.

[62] Shinozaki K, Hirayama A, Nishio Y, Yoshida Y, Ohtani T, Okamura $\mathrm{T}$, et al. Coronary endothelial dysfunction in the insulin-resistant state is linked to abnormal pteridine metabolism and vascular oxidative stress. J Am Coll Cardiol 2001;38:1821-8.

[63] Yada T, Kaji S, Akasaka T, Mochizuki S, Ogasawara Y, Tanemoto $\mathrm{K}$, et al. Changes of asymmetric dimethylarginine, nitric oxide, tetrahydrobiopterin, and oxidative stress in patients with acute myocardial infarction by medical treatments. Clin Hemorheol Micro 2007;37:269-76.

[64] Cosentino F, Hürlimann D, Delli Gatti C, Chenevard R, Blau N, Alp NJ, et al. Chronic treatment with tetrahydrobiopterin reverses endothelial dysfunction and oxidative stress in hypercholesterolaemia. Heart 2008;94:487-92.

[65] Andondonskaja-Renz B, Zeitler H-J. Separation of pteridines from blood cells and plasma by reverse-phase highperformance liquid chromatography. Anal Biochem 1983;133: 68-78.

[66] Zhao Y, Cao J, Chen Y-S, Zhu Y, Patrick C, Chien B, et al. Detection of tetrahydrobiopterin by LC-MS/MS in plasma from multiple species. Bioanalysis 2009;1:895-903.
[67] Richardson MA, Read LL, Taylor Clelland CL, Reilly MA, Chao HM, Guynn RW, et al. Evidence for a tetrahydrobiopterin deficit in schizophrenia. Neuropsychobiology 2005;52: 190-201.

[68] Omura I, Mizutani M, Goto S, Hashimoto R, Kitagami T, Miura $\mathrm{H}$, et al. Plasma biopterin levels and depressive state in pregnancy and the early puerperal period. Neuropsychobiology 2002;45:134-8.

[69] Slazyk WE, Spierto FW. Liquid-chromatographic measurement of biopterin and neopterin in serum and urine. Clin Chem 1990;36:1364-8.

[70] Mochizuki S, Ono J, Yada T, Ogasawara Y, Miyasaka T, Kimoto $\mathrm{M}$, et al. Systemic nitric oxide production rate during hemodialysis and its relationship with nitric oxide-related factors. Blood Purif 2005;23:317-24.

[71] He L, Zeng H, Li F, Feng J, Liu S, Liu J, et al. Homocysteine impairs coronary artery endothelial function by inhibiting tetrahydrobiopterin in patients with hyperhomocysteinemia. Am J Physiol 2010;299:E1061-5.

[72] Mayahi L, Mason L, Bleasdale-Barr K, Donald A, TrenderGerhard I, Sweeney MG, et al. Endothelial, sympathetic, and cardiac function in inherited (6R)-L-erythro-5,6,7, 8-tetrahydro-L-biopterin deficiency. Circulation 2010;3:513-22.

[73] Antoniades C, Bakogiannis C, Leeson P, Guzik TJ, Zhang MH, Tousoulis D, et al. Rapid, direct effects of statin treatment on arterial redox state and nitric oxide bioavailability in human atherosclerosis via tetrahydrobiopterin-mediated endothelial nitric oxide synthase coupling/clinical perspective. Circulation 2011;124:335-45.

[74] Mizutani M, Hashimoto R, Ohta T, Nakazawa K, Nagatsu T. The effect of exercise on plasma biopterin levels. Neuropsychobiology 1994;29:53-6.

[75] Hashimoto R, Mizutani M, Ohta T, Nakazawa K, Nagatsu T. Changes in plasma tetrahydrobiopterin levels of depressives in depressive and remission phases-reconfirmed by measurement with an internal standard. Neuropsychobiology 1994;29:57-60.

[76] Hashimoto R, Ozaki N, Ohta T, Kasahara Y, Kaneda N, Nagatsu T. Plasma tetrahydrobiopterin levels in patients with psychiatric-disorders. Neuropsychobiology 1990;23:140-3.

[77] Hashimoto R, Ozaki N, Ohta T, Kasahara Y, Kaneda N, Nagatsu T. Plasma biopterin levels of patients with affective-disorders. Neuropsychobiology 1988;19:61-3.

[78] Hashimoto R, Ozaki N, Ohta T, Kasahara Y, Kaneda N, Nagatsu T. Total biopterin levels of plasma in patients with depression. Neuropsychobiology 1987;17:176-7.

[79] Hoekstra R, van den Broek WW, Fekkes D, Bruijn JA, Mulder PGH, Pepplinkhuizen L. Effect of electroconvulsive therapy on biopterin and large neutral amino acids in severe, medication-resistant depression. Psychiat Res 2001;103: 115-23.

[80] Yokoyama K, Tajima M, Yoshida H, Nakayama M, Tokutome $\mathrm{G}$, Sakagami H, et al. Plasma pteridine concentrations in patients with chronic renal failure. Nephrol Dial Transpl 2002;17:1032-6.

[81] Walter R, Blau N, Kierat L, Schoedon G, Reinhart WH. Systemic tetrahydrobiopterin $\left(\mathrm{BH}_{4}\right)$ levels and coronary artery disease. Cardiology 2000;94:265-6.

[82] Cunnington C, Van Assche T, Shirodaria C, Kylintireas I, Lindsay AC, Lee JM, et al. Systemic and vascular oxidation limits the efficacy of oral tetrahydrobiopterin treatment in patients with coronary artery disease. Circulation 2012;125: 1356-66.

[83] Hoshiai K, Hattan N, Fukuyama N, Tadaki F, Hida M, Saito A, et al. Increased plasma tetrahydrobiopterin in septic shock is a possible therapeutic target. Pathophysiology 2001;7: 275-81.

[84] Mortensen A, Lykkesfeldt J. Kinetics of acid-induced degradation of tetra- and dihydrobiopterin in relation to their 
relevance as biomarkers of endothelial function. Biomarkers 2013;18:55-62.

[85] Sawabe K, Saeki Y, Ohashi A, Mamada K, Wakasugi KO, Matsuoka $\mathrm{H}$, et al. Tetrahydrobiopterin in intestinal lumen: its absorption and secretion in the small intestine and the elimination in the large intestine. J Inherit Metab Dis 2009;32: 79-85.

[86] Kim HL, Kim DH, Lee YK, Park SO, Lee YW, Kwon OS, et al. An enzymatic method to distinguish tetrahydrobiopterin from oxidized biopterins using UDP-glucose: tetrahydrobiopterin glucosyltransferase. Anal Biochem 2010;397:79-83.

[87] Schmidt TS, McNeill E, Douglas G, Crabtree MJ, Hale AB, Khoo $J$, et al. Tetrahydrobiopterin supplementation reduces atherosclerosis and vascular inflammation in apolipoprotein E-knockout mice. Clin Sci 2010;119:131-42.

[88] Haruna Y, Morita Y, Komai N, Yada T, Sakuta T, Tomita N, et al. Endothelial dysfunction in rat adjuvant-induced arthritis: vascular superoxide production by $\mathrm{NAD}(\mathrm{P}) \mathrm{H}$ oxidase and uncoupled endothelial nitric oxide synthase. Arthrit Rheumat 2006;54:1847-55.

[89] Noguchi K, Hamadate N, Matsuzaki T, Sakanashi M, Nakasone J, Sakanashi M, et al. Improvement of impaired endothelial function by tetrahydrobiopterin in stroke-prone spontaneously hypertensive rats. Eur J Pharmacol 2010;631: 28-35.

[90] Hoshiga M, Hatakeyama K, Watanabe M, Shimada M, Kagamiyama H. Autoradiographic distribution of [14C]tetrahydrobiopterin and its developmental change in mice. J Pharmacol Exp Therap 1993;267:971-8.

[91] Ohashi A, Suetake Y, Saeki Y, Harada T, Aizawa S, Hasegawa $\mathrm{H}$. Rapid clearance of supplemented tetrahydrobiopterin is driven by high-capacity transporters in the kidney. Mol Gen Metab 2012;105:575-81.

[92] Goldberg M, Fuchs C. Studies and comparison of pterin patterns in the plasma of dogs and cats and their alteration in various neoplasias and virus infections. J Vet Med 1996;43: 201-9. 